Article

\title{
Crash- and Simulation-Based Safety Performance Evaluation of Freeway Rest Area
}

\author{
Hyeonseo Kim ${ }^{1}$, Kyeongjoo Kwon ${ }^{2}{ }^{(}$, Nuri Park ${ }^{1}$, Juneyoung Park ${ }^{1,2, *}$ and Mohamed Abdel-Aty ${ }^{3}(\mathbb{D}$ \\ 1 Department of Smart City Engineering, Hanyang University, Ansan 15588, Korea; \\ pass782@naver.com (H.K.); nuripark@hanyang.ac.kr (N.P.) \\ 2 Department of Transportation and Logistics Engineering, Hanyang University, Ansan 15588, Korea; \\ koy3450@naver.com \\ 3 Department of Civil, Environmental and Construction Engineering, University of Central Florida, \\ Orlando, FL 32816, USA; M.Aty@ucf.edu \\ * Correspondence: juneyoung@hanyang.ac.kr; Tel.: +82-31-400-5151
}

Citation: Kim, H.; Kwon, K.; Park, N.; Park, J.; Abdel-Aty, M. Crash- and Simulation-Based Safety Performance Evaluation of Freeway Rest Area. Sustainability 2021, 13, 4963. https:// doi.org/10.3390/su13094963

Academic Editor: Tamás Bányai

Received: 5 April 2021

Accepted: 25 April 2021

Published: 28 April 2021

Publisher's Note: MDPI stays neutral with regard to jurisdictional claims in published maps and institutional affiliations.

Copyright: () 2021 by the authors. Licensee MDPI, Basel, Switzerland. This article is an open access article distributed under the terms and conditions of the Creative Commons Attribution (CC BY) license (https:// creativecommons.org/licenses/by/ $4.0 /)$.

\begin{abstract}
The main objective of this study was to evaluate the safety effects caused by altering the lengths of deceleration and acceleration lanes at rest areas on expressways in Korea. Although general conclusions can be found through crash-based safety analysis, to examine more specific optimal conditions considering various traffic conditions, this study proposes a novel framework to explore and evaluate crash-based and simulation-based safety performances. For this purpose, the safety performance function (SPF) and crash modification factor (CMF) were developed to reflect real-world safety impacts. To consider nonlinear trends of the parameters, nonlinearizing link functions were introduced into the analysis. Two types of simulation analyses were conducted to (1) find the combination of surrogate safety measures (SSMs) that best fit with the crash-based safety performance results and (2) determine the optimal lengths of deceleration lane and acceleration lanes for different traffic conditions. The results showed that the best length of deceleration lane of a rest area is between 240 and $260 \mathrm{~m}$, depending on the traffic conditions. The results also indicated that the optimal length of acceleration lane of a rest area is between 385 and $400 \mathrm{~m}$, depending on the traffic parameters. The findings of this study could be used to determine the safety solutions with a micro-traffic simulator.
\end{abstract}

Keywords: safety performance; traffic simulation; surrogate safety; rest area; crash modification factor

\section{Introduction}

According to the KoEX (Korea Expressway Corporation) (2019) [1], crashes caused by drowsy driving have a higher death rate than general crashes over a recent 10-year period (2007-2016) in Korea. To reduce drowsy driving crashes, the KoEX began installing rest areas in 2011. Currently, 223 rest areas are operating on expressways in Korea. Rest areas are designed to reduce drowsy driving by providing a resting place for drivers. Based on the KoEX crash data, a total of 128 crashes occurred at rest areas over a five-year period (2012-2016), and 99 of these occurred in the deceleration and acceleration lanes of the rest areas. The main cause of crashes at the entry and exit points was rapid deceleration, resulting in conflicts with mainline driving vehicles. In Korea, according to the rest area design manual (Ministry of Land, Infrastructure and Transport in Korea, 2019) [2], the current lengths of deceleration and acceleration lanes in rest areas are constructed based on a designed speed of $100 \mathrm{~km} / \mathrm{h}$. The length of the deceleration lane is $215 \mathrm{~m}$, and the length of the acceleration lane is $370 \mathrm{~m}$. The deceleration lanes (used to enter a rest area) and the acceleration lanes (used to exit a rest area) are based on a designed speed of $40 \mathrm{~km} / \mathrm{h}$. Rest areas can be broadly divided into parallel types, in which a transition section exists, and tapered types, in which a transition section does not exist. Korean rest areas are generally based on the parallel type. It should be noted that there are two types of rest facilities in 
Korea. Rest and service areas are generally bigger resting facilities that have restaurants, gas stations, toilets, convenience stores, etc., whereas rest areas are smaller resting facilities that have toilets and a few benches to take a short rest. Figure 1 shows representative images of the two types of resting facilities along Korea's expressways.

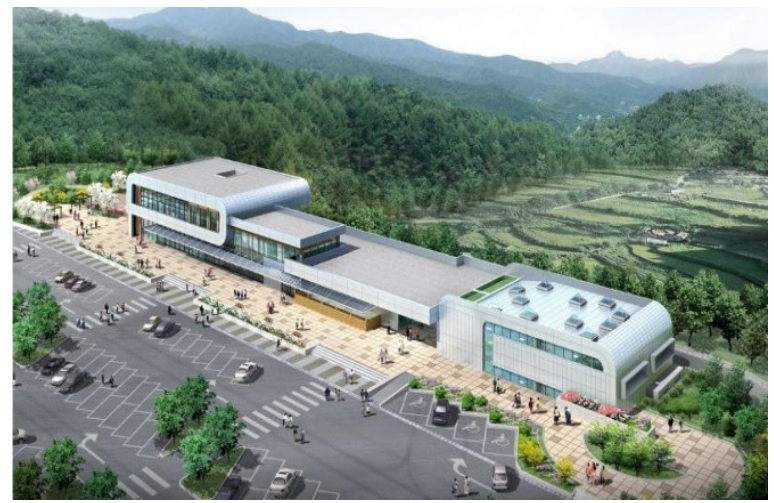

(a) Rest and service area

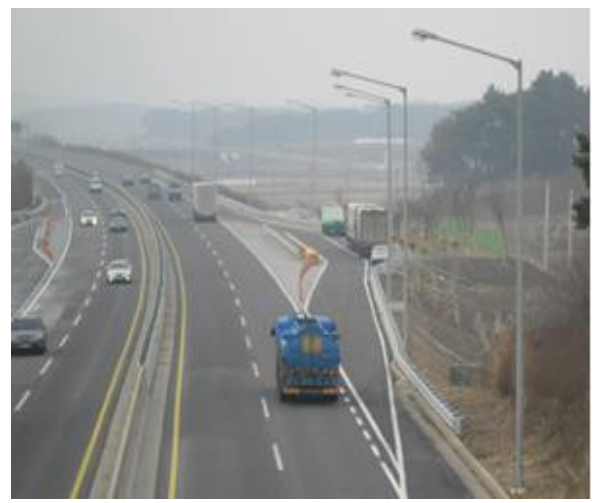

(b) Rest area

Figure 1. Resting facilities on expressways in Korea.

These guidelines were derived solely based on the speed of the mainline traffic; however, it may be necessary to consider additional factors related to rest area characteristics (especially the lengths of the deceleration and acceleration lanes). Therefore, this study proposes more appropriate deceleration and acceleration lane lengths for rest areas. To accomplish this aim, this study first developed crash modification factors (CMFs) for altered length of deceleration and acceleration lanes by assessing safety performance functions (SPFs) [3]. Since the developed CMFs can only represent generalized lengths of deceleration and acceleration lanes based on the overall safety performance, micro-traffic simulation was also used to consider various traffic volumes and heavy vehicle ratios. The detailed study design is presented in later sections.

The remainder of this study is organized as follows. The second section reviews related studies in the literature. The third section presents our research framework and methodologies. The fourth section describes the data preparation process, and the fifth section discusses the analysis results. The final section concludes this study.

\section{Literature Review}

\subsection{Design Criteria of Highway Resting Facilities}

In the United States [4], the proper lengths of deceleration and acceleration lanes are determined by considering safety factors when installing rest areas, based on its wide land characteristics. The design criteria for deceleration and acceleration lanes are based on the design criteria for the interchanges where traffic enters and exits the highway. The minimum lengths of deceleration and acceleration lane are $145 \mathrm{~m}$ and $285 \mathrm{~m}$, respectively, when the interchange designed speed is $40 \mathrm{~km} / \mathrm{h}$ and the mainline designed speed is $100 \mathrm{~km} / \mathrm{h}$. Additionally, Romo-Martin and Perez-Acebo (2018) [5] specified the necessary conditions for the service areas of Spanish highways. The appropriate lengths of deceleration and acceleration lanes were calculated by taking the slope, entry speed, arrival speed, and speed limit into consideration. As a result, it was found that the estimated length of acceleration lane was $200 \mathrm{~m}$ at a speed limit of $100 \mathrm{~km} / \mathrm{h}$, whereas the appropriate length of deceleration lane was $100 \mathrm{~m}$ at a speed limit of $80 \mathrm{~km} / \mathrm{h}$. For the transition section, the appropriate length of deceleration is $83 \mathrm{~m}$ and the length of acceleration section is $167 \mathrm{~m}$ at a speed limit of $100 \mathrm{~km} / \mathrm{h}$. The service areas in Japan are small-scale rest facilities similar to rest areas in Korea [6]. The lengths of deceleration and acceleration lanes were calculated by considering the designed speed of the mainline and connector roads. When the mainline designed speed is $100 \mathrm{~km} / \mathrm{h}$ and the connector road designed 
speed is $40 \mathrm{~km} / \mathrm{h}$, the minimum lengths of deceleration and acceleration lanes are $140 \mathrm{~m}$ and $230 \mathrm{~m}$, respectively.

Table 1 compares the length of deceleration and acceleration lanes for rest facilities in Korea and other countries. The reason Korea is shorter than other countries is that the United States assumes that it starts to decelerate from the mainline, and Japan is the minimum standard.

Table 1. Design criteria of highway resting facilities.

\begin{tabular}{ccc}
\hline & \multicolumn{2}{c}{ Mainline Design Speed $\mathbf{1 0 0 ~} \mathbf{~ k m} / \mathbf{h}$} \\
\cline { 2 - 3 } & Lengths of Deceleration Lane $\mathbf{( m )}$ & Lengths of Acceleration Lane (m) \\
\hline Korea & 215 & 370 \\
United States & 145 & 285 \\
Japan & 140 (Minimum Length) & 230 (Minimum Length) \\
\hline
\end{tabular}

\subsection{Studies on the Safety Performance Function (SPF) and Crash Modification Factor (CMF)}

La Torre et al. (2017) [7] derived crash modification factors (CMFs) by using the Emerical Bayes (EB) before-and-after method to evaluate changes in the expected crash frequency associated with the installation of an Italian highway stationary work zone. Manuel et al. (2014) [8] developed the negative binomial (NB) safety performance functions (SPFs) based on the cross-sectional evaluation method to derive safety implications of oversized collectors from the City of Edmonton, in Canada. Manan et al. (2013) [9] developed a safety performance function (SPF) for motorcycle fatal crash data on major roads in Malaysia primary road, using negative binomial regression analysis. El-Basyouny and Sayed (2012) [10] proposed a novel approach based on a linear intervention model that can calculate the direct and indirect treatment effect for safety performance function (SPF), using case studies in Iowa and British Columbia. Intini et al. (2019) [11] compared the characteristics of the prediction accuracy of transferred and local SPFs based on two-lane rural road sites in Italy and Scotland, taking into account European geographic variability.

\subsection{Studies on the Acceleration and Deceleration Lane Design Criteria of Highway Rest Facilities}

Han and Kim (2018) [12] constructed scenarios for the entry and exit lengths and extracted individual vehicle trajectory data of vehicles, using the deceleration and acceleration lanes to calculate the acceleration noise of vehicles by using VISSIM. By analyzing the calculated acceleration noise, they determined that the appropriate lengths of deceleration and acceleration lanes were $245 \mathrm{~m}$ and $370 \mathrm{~m}$, respectively. Seo (2018) [13] analyzed driving performance factors such as driving speed, deceleration and acceleration patterns, and entry/exit positions of vehicles in the deceleration and acceleration lanes of rest areas by using a portable detector. Additionally, to calculate the design criteria for the appropriate lengths of deceleration and acceleration lanes, the characteristics of heavy vehicles that have relatively low acceleration capabilities were considered in the case of acceleration lanes, while the deceleration lanes were calculated based on a general vehicle type. As a result, the appropriate lengths of deceleration and acceleration lanes were $225 \mathrm{~m}$ and $380 \mathrm{~m}$, respectively. Lee and Won (2013) [14] reviewed the design criteria of service areas outside the country and derived the appropriate components of the design criteria for domestic situations. In addition, they reviewed the appropriateness of the geometric structure of service areas by surveying the driving behavior of individual vehicles. They suggested that the length of entry connector roads (considering the driving speed) and the range of the junction setting angles of entrance connector roads are important design criteria. Lee et al. (2012) [15] classified the design section of the service area's entry and exit sections. They also derived design elements for each section, and then each element's minimum standard was derived. These results showed that the minimum length of the entry lane is $40 \mathrm{~m}$ and the junction setting angle is $12^{\circ}$ to $17^{\circ}$. 


\subsection{Studies on Acceleration and Deceleration Lanes of Other Highway Facilities}

Luo et al. (2019) [16] evaluated the optimal length of the acceleration lane on an expressway weaving area, using the empirical survey data and a microscopic simulation system, called Traffic Parallel Simulation System (TPSS). Yang et al. (2018) [17] revealed that a constant acceleration rate is not reasonable in providing appropriate freeway entrance ramp acceleration lengths using statistical analysis of the individual vehicle-accelerating trajectories. Qi et al. (2019) [18] estimated the freeway acceleration lane length for safe merging by vehicle type. To this end, a literature review was conducted on the existing design guidelines on freeway acceleration lane and the existing methods for estimating the freeway acceleration lane length. Moreover, a case study was conducted in Houston, TX, to demonstrate the model reliability. Chen et al. (2014) [19] analyzed the crash data in terms of safety and the total delay of passing traffic in terms of transportation operation by simulation (TSIS/CORSIM) as a measure of effectiveness (MOE). As a result of the analysis, the appropriate lengths of parallel and tapered deceleration and acceleration lanes were derived. Hu et al. (2013) [20] estimated the appropriate change in lane length of a highway trumpet interchange by considering the driver's workload and initial speed. Zhou et al (2013) [21] estimated the appropriate lengths of the deceleration and acceleration lanes of the left-side ramp by considering the characteristics of the driver and the speed for the merge/diverge section on the left side of on/off ramps; they claimed that having an auxiliary lane is important in the left-side ramp. Hassan et al. (2012) [22] estimated the lengths of deceleration and acceleration lanes of a speed-change lane (SCL), using the firstorder second-moment (FOSM) theory, which is a probability-based theory, and compared these results with field data. Similar to this study, Salehi (2010) [23] used a probabilistic method to highway geometric design (instead of the current deterministic methodology) to estimate the lengths of acceleration speed change lanes (SCL). They then evaluated derived results through reliability-based analysis. As a result, the SCL length criterion currently applied collectively is not suitable. Moreover, traffic volume, SCL geometry, and current are required to derive the fitted SCL length for a safe merging maneuvre.

There have been several studies used to estimate the appropriate lengths of deceleration and acceleration lanes in rest areas and other highway facilities. There have been some analyses using only simulations. However, no study has analyzed the optimized lengths of deceleration and acceleration lanes by considering both crash-based and simulation-based safety performances simultaneously. Moreover, most previous studies did not consider various traffic parameters in their analysis. Thus, based on the review above, it is necessary to conduct simulation analysis and crash data analysis concurrently so that rest areas with various lengths of deceleration and acceleration lanes can be analyzed. Additionally, it is necessary to consider the type of entry and exit lanes of the rest areas.

\section{Research Framework and Methodology}

\subsection{Research Framework}

This study attempted to explore and evaluate crash-based and simulation-based safety performance when altering the lengths of deceleration and acceleration lanes. The overall framework of this study is as follows. First, the CMF values (i.e., the crash-based safety performance) for lengths of deceleration and acceleration lane were estimated by the cross-sectional method, using the crash data. Second, an initial simulation analysis was conducted to find the optimal combination of surrogate safety measures (SSMs) that reflect real-world safety impacts properly. Lastly, based on the best combination of SSMs, additional simulations were assessed while considering various traffic parameters (i.e., the heavy vehicle rate, mainline traffic volume, and rest area traffic volume) (Figure 2). 


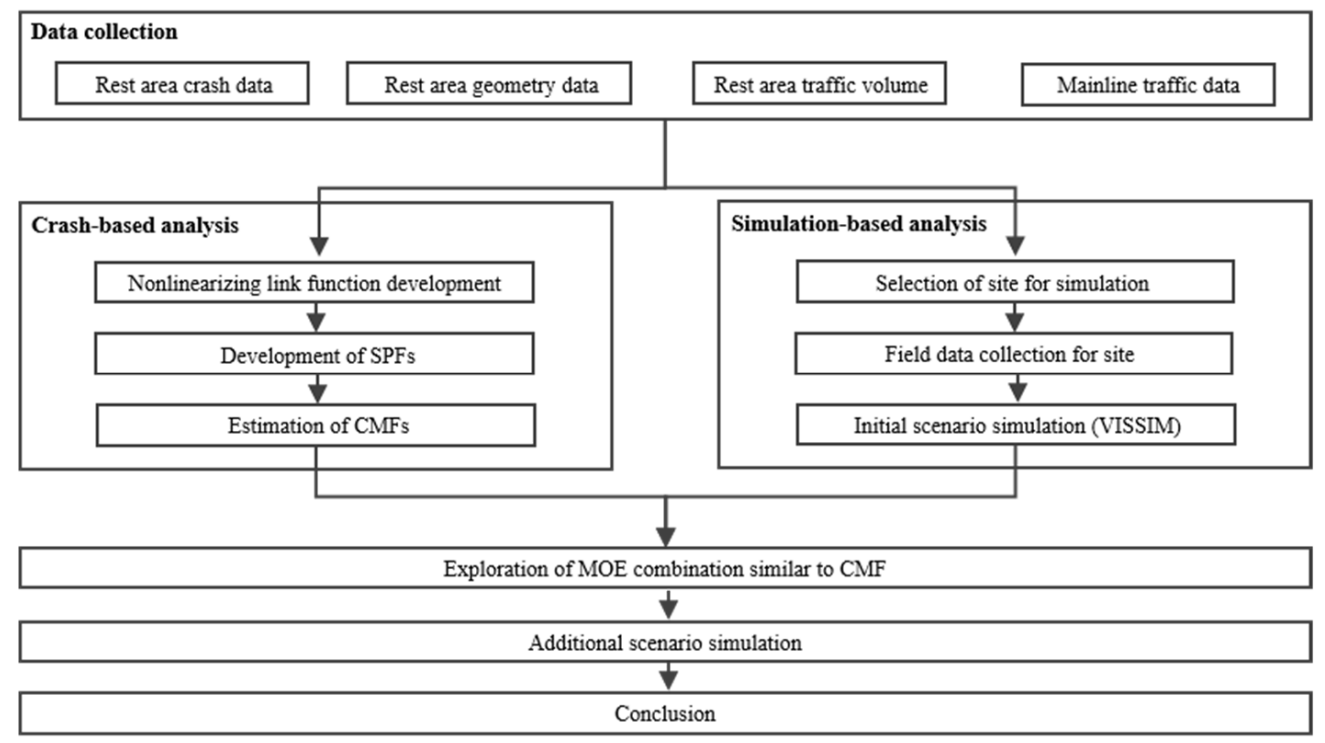

Figure 2. Research flowchart.

\subsection{VISSIM Calibration and Validation}

VISSIM is a micro-traffic simulator used to analyze an actual road by virtually implementing it in the simulator; actual traffic situations should be reflected in the simulation. To perform the micro-simulation analysis, calibration and validation processes are required.

The car-following model applied to expressway by VISSIM is the Wiedemann 99 model, and related variables include CC0 to CC9 and look-ahead distance, look-back distance, and temporary lack of attention. In this study, the Wiedemann 99 car-following model presented by VISSIM was set as the default value. The vehicle speed distribution was performed by adopting the corrected vehicle speed distribution studied by the park et al. (2013); the speed distribution of passenger cars was set to $90-155 \mathrm{~km} / \mathrm{h}$, the speed distribution of trucks was set to $80-110 \mathrm{~km} / \mathrm{h}$, and the speed distribution of buses was set to $95-120 \mathrm{~km} / \mathrm{h}$ [24]. In order to reflect the actual lane-changing driver's behavior of the vehicle entering the rest area, both the transition section and the deceleration lane were set to allow the vehicle to enter. Similarly, vehicles entering the mainline were also set to be able to enter both the transition section and the acceleration lane. To validate the VISSIM network, the error rate method was adopted to compare the field section speed with simulated data [25]. The error rate was determined to be 0.996 , with a confidence level of $95 \%$, which indicates a well-calibrated model.

\subsection{CMF Development Method}

According to the Highway Safety Manual (HSM) [3], a CMF can express the effect on the number of crashes when specific conditions change on a roadway section. Methods for estimating CMF are observational before-after studies and cross-sectional [26-28]; the cross-sectional method was applied to calculate CMFs because it can obtain data more easily than before-after approaches [29].

To develop CMFs using the cross-sectional method, the development of SPFs is required. In general, SPFs are developed by using negative binomial (NB) distribution models. However, since several researchers have recommended applying a generalized nonlinear model (GNM) to account for nonlinear effects of the independent variable [30-32], this study developed a nonlinearizing link function to assess GNMs. The nonlinearizing link function can be described in any functional form, including linear, quadratic, log, power, etc., for different values of y [30]. The functional form of nonlinearizing link function $(\mathrm{U}(\mathrm{y}))$ is determined based on the relationship between the logarithm of the crash 
rate and the variable $y$. The functional form of the SPF for the NB regression model with the nonlinearizing link function is shown in Equation (1), as follows:

$$
N_{\text {predicted }, i}=\exp \left(\beta_{0}+\beta_{1} \ln \left(A A D T_{i}\right)+\beta_{k}\left(X_{k i}\right)+\gamma_{i}\left(U\left(y_{l i}\right)\right)\right)
$$

where $N_{\text {predicted, } i}$ is the predicted crash frequency on segment $i, \beta_{k}$ is the coefficients for the variable $\mathrm{k}, A A D T_{i}$ is the annual average daily traffic of segment $\mathrm{i}$ (veh/day), $\gamma_{i}$ : coefficients for the nonlinear predictor $\mathrm{i}, y_{l i}$ is the nonlinear predictor 1 of segment $\mathrm{i}$, and $X_{k i}$ is the linear predictor $\mathrm{k}$ of segment $\mathrm{i}$. as follows:

Since $\mathrm{U}(\mathrm{y})$ varies with $\mathrm{y}$, the CMF, using the GNM, can be estimated by Equation (2),

$$
\mathrm{CMF}=\exp \left\{\gamma_{i} \times\left(\mathrm{U}\left(y_{l t}\right)-\mathrm{U}\left(y_{l b}\right)\right)\right\}
$$

where $y_{l t}$ is the nonlinear predictor 1 of treated sites, and $y_{l b}$ is the nonlinear predictor 1 of untreated sites (baseline condition).

\section{Data Preparation}

The study areas were set according to the location of rest area signs and defined by using the method for setting the influence area of freeway mainlines [2,33]. The deceleration lane is the region from $500 \mathrm{~m}$ upstream of the ramp-freeway junction to $100 \mathrm{~m}$ downstream of this point. Alternatively, the acceleration lane is the region from $100 \mathrm{~m}$ upstream of the ramp-freeway junction to $500 \mathrm{~m}$ downstream of this point.

Table 2 presents the descriptive statistics of deceleration and acceleration lanes. A total of 192 rest areas were investigated for this study. Traffic volumes of rest areas were collected through the traffic monitoring system (TMS) [1], and the geometries of the rest areas were collected from satellite image maps. Traffic volume was set the same as the crash data period (2012-2016), and the ADT (average daily traffic) was derived by selecting July as the representative traffic volume without any special circumstances. Data collection results showed that 102 parallel-type deceleration lanes and 147 parallel-type acceleration lanes were found among the 192 rest areas.

Table 2. Descriptive statistics of deceleration and acceleration lanes.

\begin{tabular}{ccccccccc}
\hline & \multicolumn{3}{c}{ Deceleration Lane } & & \multicolumn{2}{c}{ Acceleration Lane } \\
\hline Parameter & Mean & SD & Minimum & Maximum & Mean & SD & Minimum & Maximum \\
\hline ADT (veh/day) & 23,328 & $20,398.94$ & 3452 & 95,767 & 22,694 & $18,834.82$ & 3452 & 87,406 \\
Length (m) & 177.55 & 42.55 & 50 & 350 & 225.89 & 71.16 & 90 & 480 \\
\hline
\end{tabular}

Table 3 presents statistics of the number of crashes at the target site. The number of crashes used 5 years of highway crash data (2012-2016) provided by KoEX. Both the paralleltype acceleration and deceleration lanes caused the most crashes on the acceleration lanes than in other sections, and the maximum and minimum number of crashes was the same.

Table 3. Statistics of the number of crashes at the target site.

\begin{tabular}{ccccccccc}
\hline & \multicolumn{3}{c}{ Parallel-Type Deceleration Lane } & \multicolumn{3}{c}{ Parallel-Type Acceleration Lane } \\
\hline $\begin{array}{c}\text { Number of Crashes } \\
\text { by Rest Area Sections }\end{array}$ & Mean & SD & Minimum & Maximum & Mean & SD & Minimum & Maximum \\
\hline Deceleration lane & 3.03 & 3.14 & 0 & 14 & 3.31 & 3.19 & 0 & 14 \\
Inside the rest area & 0.73 & 1.21 & 0 & 7 & 0.78 & 1.19 & 0 & 7 \\
Acceleration lane & 3.33 & 5.61 & 0 & 52 & 3.47 & 4.92 & 0 & 52 \\
\hline
\end{tabular}

In this study, field data for the construction of the VISSIM network were collected at a section of a two-lane expressway with a rest area. The Moga rest area located on the Jungbu expressway was selected to be the simulation site. Its deceleration and acceleration 
lanes are tapered, and the lengths of deceleration and acceleration lanes are $180 \mathrm{~m}$ and $240 \mathrm{~m}$, respectively. There are five parking lots for passenger cars (total length of $30 \mathrm{~m}$ ) and three parking lots for heavy vehicles (total length of $36 \mathrm{~m}$ ).

\section{Results and Discussions}

\subsection{CMF Development}

In this study, a linear SPF was first developed by using the length of acceleration (or deceleration) lane as the independent variable and the traffic volume information (average daily traffic (ADT)) through the NB regression. However, after plotting crash data, it was confirmed that the data show a general nonlinear shape in both deceleration and acceleration lanes. For this reason, nonlinearizing link functions were calculated and used to develop nonlinear SPFs to reflect the nonlinear characteristics of the crash data.

By comparing the adjusted r-squared values of 12 linear and nonlinear functional forms, the fitted model was found [34]. The results showed that the log model was the bestfitted function for both deceleration and acceleration lanes. The developed nonlinearizing link functions for deceleration and acceleration lanes are shown in Equations (3) and (4).

Based on the developed nonlinearizing link functions, the nonlinear SPFs were evaluated. Table 4 presents the developed NB models with lengths of deceleration and acceleration lane. In general, the parameters are statistically significant at a $90 \%$ confidence level. For the SPFs with lengths of deceleration and acceleration lane, only the interaction term with the traffic volume and nonlinearizing link function was significant. It is worth noting that both the lengths of deceleration and acceleration lanes were included as normal linear parameters to develop SPFs; however, they were not statistically significant.

$$
\mathrm{U}_{\mathrm{dec}}=11.36016+(-1.6156) \log _{\mathrm{x}}
$$

where $U_{d e c}$ is the nonlinearizing link function for changes of the length of deceleration lane, and $\mathrm{X}$ is the length of deceleration lane $(\mathrm{m})$.

$$
\mathrm{U}_{\mathrm{acc}}=18.461+(-2.8537) \log _{\mathrm{x}}
$$

where $U_{a c c}$ is the nonlinearizing link function for changes of the length of acceleration lane, and $\mathrm{X}$ is the length of acceleration lane $(\mathrm{m})$.

\begin{tabular}{|c|c|c|c|c|}
\hline \multirow[b]{2}{*}{ Parameter } & \multicolumn{2}{|c|}{ SPF with Length of Deceleration Lane } & \multicolumn{2}{|c|}{ SPF with Length of Acceleration Lane } \\
\hline & Coefficient & SE & Coefficient & SE \\
\hline Intercept & -2.0972 & 0.8032 & -3.1192 & 0.8227 \\
\hline$U_{d e c}{ }^{*} \operatorname{Ln}(\mathrm{ADT})$ & 0.0425 & 0.0105 & \multicolumn{2}{|c|}{$\mathrm{N} / \mathrm{A}^{1}$} \\
\hline$U_{a c c}{ }^{*} \operatorname{Ln}(\mathrm{ADT})$ & \multicolumn{2}{|c|}{$\mathrm{N} / \mathrm{A}^{1}$} & 0.0369 & 0.007 \\
\hline Dispersion & \multicolumn{2}{|c|}{0.5938} & \multicolumn{2}{|c|}{0.3762} \\
\hline AIC & \multicolumn{2}{|c|}{441.4316} & \multicolumn{2}{|c|}{622.5627} \\
\hline
\end{tabular}

Table 4. Nonlinear NB models.

${ }^{1} \mathrm{~N} / \mathrm{A}$, not available; AIC, Akaike information criterion.

Because deceleration and acceleration lanes interact with the ADT, the CMF for altered lengths of deceleration and acceleration lanes can be developed based on different ADT levels. Based on the mean ADT value from Table 2, the ADT range was classified into two sub-ranges: the ADT level of the deceleration lane (3000-24,000 veh/day and 24,001$96,000 \mathrm{veh} /$ day) and the ADT level of the acceleration lane (3000-23,000 veh/day and 23,001-88,000 veh/day). Additionally, the most frequent levels in each group were selected from low and high traffic volumes [35].

The CMF results for altered lengths of deceleration and acceleration lane showed that the CMFs decreased as the length of baseline increased. Therefore, the CMF value is the lowest when the length of deceleration lane is $260 \mathrm{~m}$ and the length of acceleration lane is $400 \mathrm{~m}$. Standard error values of all developed CMFs were estimated to be less than 
0.05 , indicating highly reliable results. Figure 3 visualizes CMFs with altered lengths of deceleration and acceleration lane with low and high traffic volumes. Figure 4 visualizes CMFs for altered lengths of deceleration and acceleration lanes with the ADT. It was identified that the safety performance for increasing lengths of deceleration and acceleration lanes decreases when the ADT is too low or too high.

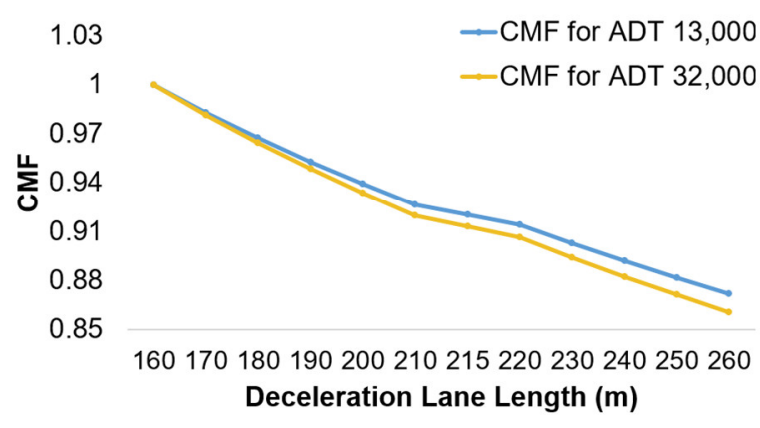

(a) Deceleration lane

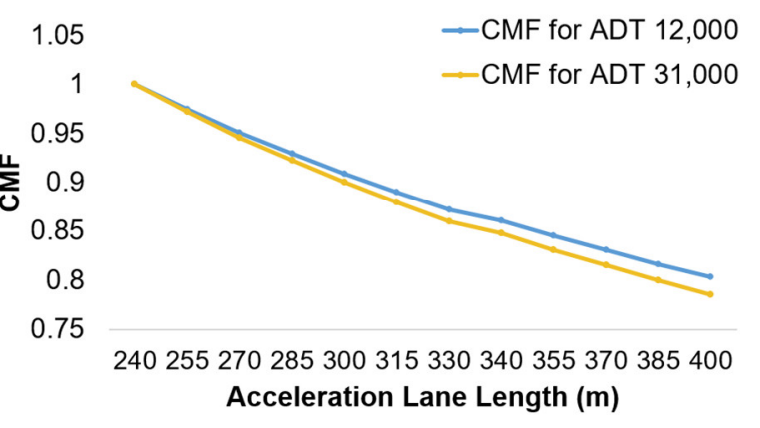

(b) Acceleration lane

Figure 3. CMF values for altered lengths of deceleration and acceleration lanes with low and high traffic volumes.

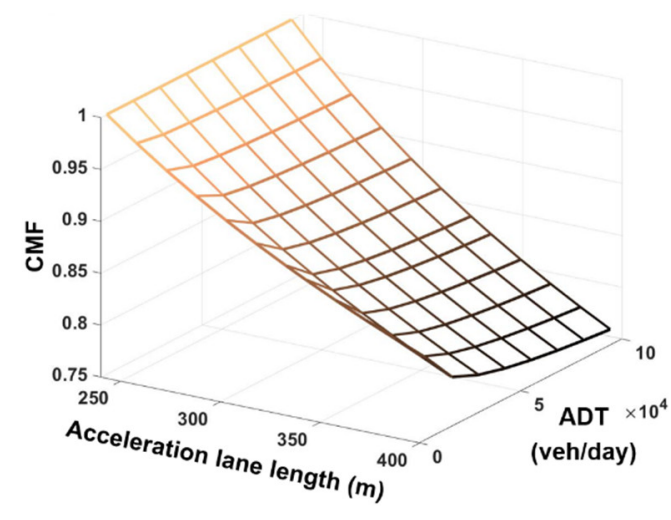

(a) Deceleration lane

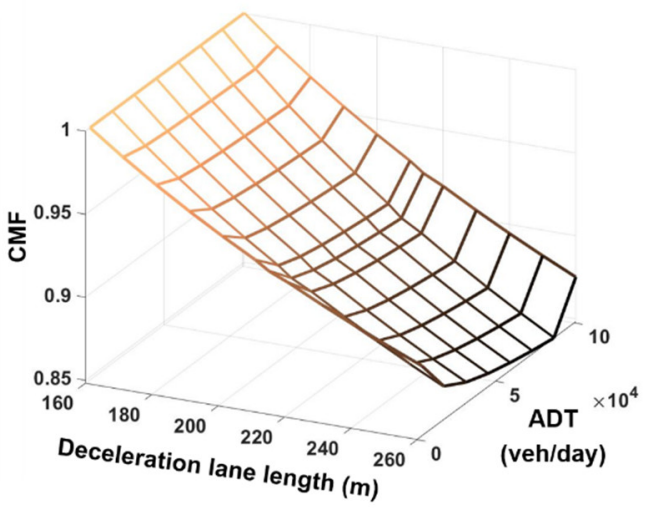

(b) Acceleration lane

Figure 4. CMF values for altered lengths of deceleration and acceleration lane with the ADT initial simulation.

Based on the field data, the present study constructed 72 scenarios for the initial simulation analysis, as shown in Tables 5 and 6 . The deceleration and acceleration lane type was parallel because this type is usually used for rest areas, according to the installation and management guidelines of highway rest areas [2]. The length of the transition section was fixed at $70 \mathrm{~m}$ (i.e., the appropriate length of transition when the designed speed of the mainline is $100 \mathrm{~km} / \mathrm{h}$ ), and different lengths of deceleration and acceleration lanes were constructed for 12 scenarios, respectively, for analysis. The lengths of the deceleration- and acceleration-lane scenarios were set based on the results of the field data from the Moga rest area. The traffic volume and rest area utilization rate were fixed at $2000 \mathrm{vph}$ and $2 \%$, respectively, and the heavy vehicle rate was divided into three cases: $25 \%, 40 \%$, and $55 \%$.

Table 5. Deceleration lane initial simulation scenarios.

\begin{tabular}{|c|c|c|c|c|c|c|c|c|c|c|c|c|}
\hline Mainline Traffic Volume (vph) & \multicolumn{12}{|c|}{2000} \\
\hline Rest Area Traffic Volume Rate (\%) & \multicolumn{12}{|c|}{2} \\
\hline Heavy Vehicle Rate (\%) & \multicolumn{4}{|c|}{25} & \multicolumn{4}{|c|}{40} & \multicolumn{4}{|c|}{55} \\
\hline Length of Deceleration Lane (m) & 160 & 170 & 180 & 190 & 200 & 210 & 215 & 220 & 230 & 240 & 250 & 260 \\
\hline Length of Acceleration Lane (m) & \multicolumn{12}{|c|}{240} \\
\hline
\end{tabular}


Table 6. Acceleration lane initial simulation scenarios.

\begin{tabular}{|c|c|c|c|c|c|c|c|c|c|c|c|c|}
\hline Mainline Traffic Volume (vph) & \multicolumn{12}{|c|}{2000} \\
\hline Rest Area Traffic Volume Rate (\%) & \multicolumn{12}{|c|}{2} \\
\hline Heavy Vehicle Rate (\%) & \multicolumn{4}{|c|}{25} & \multicolumn{4}{|c|}{40} & \multicolumn{4}{|c|}{55} \\
\hline Length of Acceleration Lane (m) & 240 & 255 & 270 & 285 & 300 & 315 & 330 & 345 & 360 & 370 & 385 & 400 \\
\hline Length of Deceleration Lane (m) & \multicolumn{12}{|c|}{180} \\
\hline
\end{tabular}

In this study, seven SSMs, known as measures of effectiveness of the simulation study, were selected to assess the safety for different lengths of deceleration and acceleration lanes at rest areas (Table 7) [36,37]. Ten simulation runs with random speed numbers and three-hour (10,800 s) simulation times were performed to collect a sufficient amount of simulated data. Figures 5 and 6 present the initial simulation results. These results showed that the majority of the MOEs did not provide any noticeable trends for altered lengths of deceleration and acceleration lanes, and the result of each MOE was different. In addition, these results were not similar to the CMF results (Figure 3). This indicates that it is difficult to calculate the appropriate lengths of deceleration and acceleration lanes by using simulation-based safety performance when selecting only one SSM as the best MOE for simulation analysis. Therefore, this study combined several MOEs to derive a best-fitted MOE combination formula that showed similar results to the CMF results (i.e., the crash-based safety performance).

Table 7. SSMs.

\begin{tabular}{cc}
\hline MOE & Definition \\
\hline $\begin{array}{c}\text { Acceleration noise } \\
\text { Jerk }\end{array}$ & $\cdot$ The standard deviation of acceleration for the average acceleration \\
Collisions & $\cdot$ The rate of change of acceleration \\
TTC & $\cdot$ The minimum time-to-collision value observed during the conflict \\
PET & $\cdot$ The minimum post encroachment time observed during the conflict \\
DeltaS & $\cdot$ The magnitude of the difference in vehicle velocities (or trajectories) \\
MaxDeltaV & $\cdot$ The maximum DeltaV value of either vehicle in the conflict \\
\hline
\end{tabular}

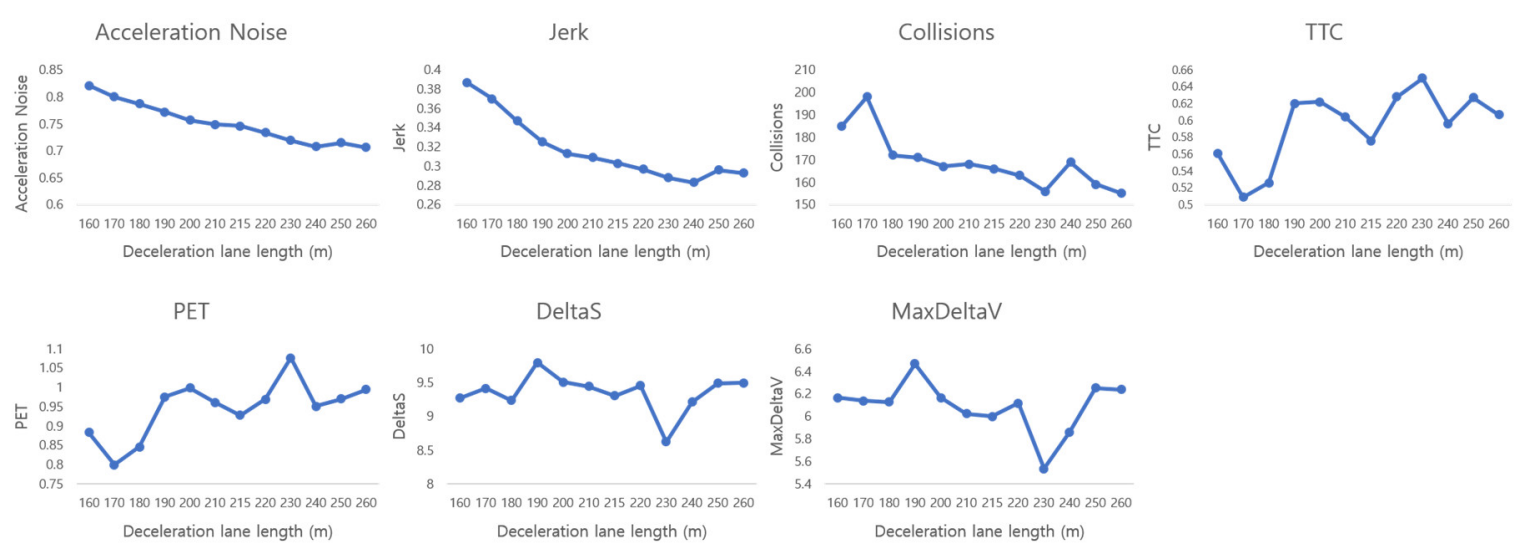

Figure 5. Initial simulation results with altered deceleration lengths of lane. 


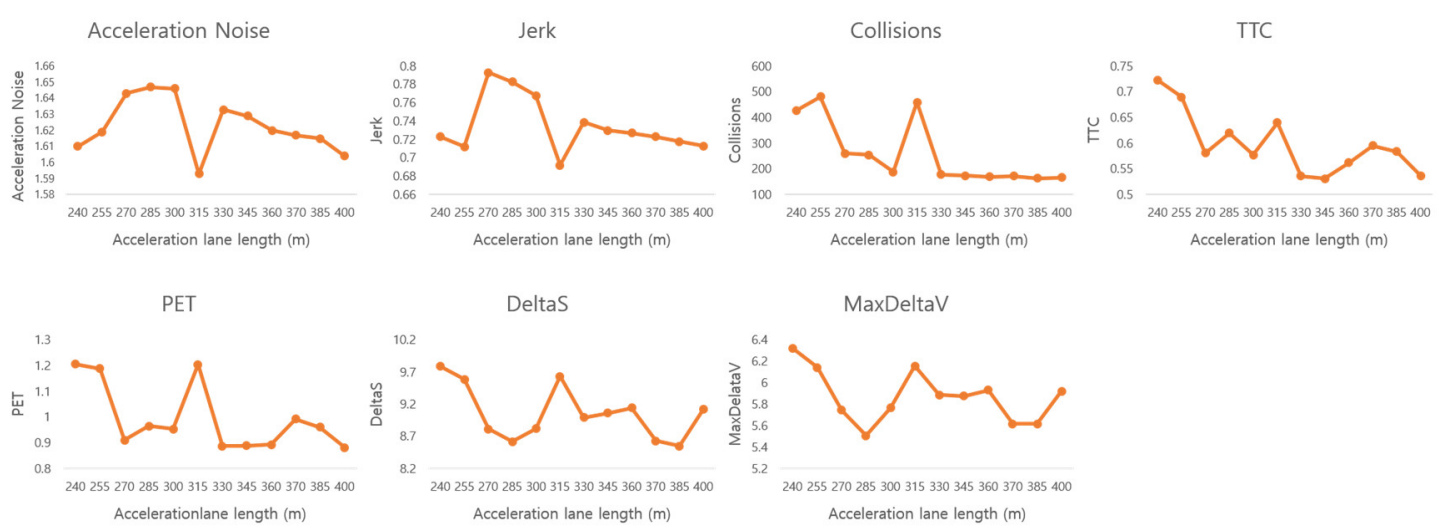

Figure 6. Initial simulation results with altered lengths of acceleration lane.

\subsection{Exploration of Crash-Based Safety with Simulation-Based Safety}

Using the developed CMFs and the different calculated SSMs, we tried various MOE combination formulas to find the MOE combination that fit best with the real-world safety performance. It was found that Equations (5) and (6) are the best-fitted MOE combinations for altered lengths of deceleration and acceleration lanes. The optimal functions were found by comparing the adjusted $r$-squared values of each combination. The final adjusted r-squared values were 0.96 for the deceleration lane and 0.87 for the acceleration lane.

$$
y_{\text {dec }}=3 \times \text { Acceleration Noise }+ \text { jerk }
$$

where $y_{d e c}$ is the best MOE combination index for determining the safety impact of the length of the deceleration lane.

$$
y_{a c c}=3 \times T T C+\frac{\text { Collisions }}{1000}+\frac{1}{P E T}+6 \times \text { Acceleration Noise }+\frac{\text { Jerk }}{\text { MaxDeltaV }}+0.3 \times \text { DeltaS }
$$

where $y_{a c c}$ is the best MOE combination index for determining the safety impact of the length of the acceleration lane.

\subsection{Additional simulations}

To examine specific optimal lengths of the deceleration lane and acceleration lane for various traffic conditions, additional simulation scenarios were designed based on different mainline traffic volumes (2000 vph and $2400 \mathrm{vph}$ ) and rest area traffic volume rates $(2 \%$ and 3\%). Tables 8 and 9 show the results of the combined MOE indices, using Equations (5) and (6). The lane length of the lowest MOE index is the appropriate lane length.

According to the results, it was confirmed that both the acceleration and deceleration lanes were more affected by the mainline traffic volume than the rest area traffic volume in calculating the appropriate lane length, and the greater the mainline traffic volume, the longer the appropriate lane length. This is because the merging and diverging that occurs during the use of rest area has more impact on the mainline.

\begin{tabular}{|c|c|c|c|c|c|c|c|c|c|c|c|c|c|}
\hline \multirow{2}{*}{$\begin{array}{l}\text { Mainline Traffic } \\
\text { Volume } \\
\text { (vph) }\end{array}$} & \multirow{2}{*}{$\begin{array}{l}\text { Rest Area Traffic } \\
\text { Volume Rate (\%) }\end{array}$} & \multicolumn{12}{|c|}{ Deceleration Lane Length (m) } \\
\hline & & 160 & 170 & 180 & 190 & 200 & 210 & 215 & 220 & 230 & 240 & 250 & 260 \\
\hline \multirow{2}{*}{2000} & 2 & 2.850 & 2.770 & 2.708 & 2.641 & 2.584 & 2.556 & 2.541 & 2.499 & 2.445 & 2.407 & 2.441 & 2.441 \\
\hline & 3 & 2.838 & 2.777 & 2.725 & 2.650 & 2.589 & 2.565 & 2.552 & 2.509 & 2.461 & 2.422 & 2.456 & 2.424 \\
\hline \multirow{2}{*}{2400} & 2 & 2.842 & 2.776 & 2.745 & 2.645 & 2.590 & 2.606 & 2.601 & 2.519 & 2.528 & 2.439 & 2.475 & 2.427 \\
\hline & 3 & 2.862 & 2.788 & 2.757 & 2.640 & 2.581 & 2.589 & 2.582 & 2.489 & 2.491 & 2.390 & 2.417 & 2.382 \\
\hline
\end{tabular}

Table 8. Results of the combined MOE index for altered lengths of deceleration lane. 
Table 9. Results of the combined MOE index for altered lengths of acceleration lane.

\begin{tabular}{|c|c|c|c|c|c|c|c|c|c|c|c|c|c|}
\hline \multirow{2}{*}{$\begin{array}{l}\text { Mainline Traffic } \\
\text { Volume } \\
\text { (vph) }\end{array}$} & \multirow{2}{*}{$\begin{array}{l}\text { Rest Area Traffic } \\
\text { Volume Rate (\%) }\end{array}$} & \multicolumn{12}{|c|}{ Acceleration Lane Length (m) } \\
\hline & & 240 & 255 & 270 & 285 & 300 & 315 & 330 & 345 & 360 & 370 & 385 & 400 \\
\hline \multirow{2}{*}{2000} & 2 & 16.137 & 16.098 & 15.742 & 15.760 & 15.623 & 15.772 & 15.534 & 15.508 & 15.561 & 15.385 & 15.338 & 15.391 \\
\hline & 3 & 16.209 & 16.309 & 15.897 & 15.668 & 15.571 & 16.125 & 15.574 & 15.517 & 15.419 & 15.342 & 15.270 & 15.497 \\
\hline \multirow{2}{*}{2400} & 2 & 16.249 & 16.338 & 15.788 & 15.841 & 15.734 & 16.215 & 15.857 & 15.609 & 15.596 & 15.598 & 15.599 & 15.552 \\
\hline & 3 & 15.817 & 15.886 & 15.715 & 15.742 & 15.695 & 15.562 & 15.527 & 15.473 & 15.329 & 15.366 & 15.283 & 15.233 \\
\hline
\end{tabular}

\section{Conclusions}

The main objective of this study was to evaluate the safety effectiveness of deceleration and acceleration lanes with altered lengths along rest areas on expressways in Korea. Although general conclusions can be found from crash-based safety analysis, to examine more specific optimal conditions considering various traffic conditions, this study proposes a novel framework to explore and evaluate crash-based and simulation-based safety performances.

For this purpose, SPFs and CMFs were developed to reflect real-world safety impacts. To consider the nonlinearities of parameters, nonlinearizing link functions were introduced in the analysis.

Two types of simulation analyses were conducted to (1) find the best-fitted MOE (SSM) combination and (2) determine the optimal lengths of deceleration and acceleration lanes for different traffic conditions. The results showed that the length of best deceleration lane of rest areas is from 240 to $260 \mathrm{~m}$, depending on the traffic conditions. The results also indicated that a range of 385 to $400 \mathrm{~m}$ was found to be the optimal length of acceleration lane of rest areas, depending on the traffic parameters. Additionally, an analysis framework was developed by matching simulation results with actual accident data to derive efficient MOEs suitable for the analysis conditions. This could be used for various similar studies in the future.

This study can be used to determine safety solutions by using a micro-traffic simulator. Further studies and limitations of this study are described as follows. First, although there are two types of entry and exit designs for rest areas, i.e., parallel and tapered, only the parallel type was considered in this study. Second, in this study, a micro-traffic simulator (i.e., VISSIM) was used to estimate the simulation-based safety performance of rest areas. Although this study suggested a new method to reflect the real-world safety in simulation results, it still cannot fully reflect the actual situation. Thirdly, in this paper, crash-based analysis results were concluded by collecting geometry characteristics of multiple sites, and simulation-based results were analyzed by combining various conditions on a validated site. As such, the results of this study correspond to various sites in Korea, so it is possible to use the results on other sites in Korea. However, applying the results to other countries may require confirmation of transferability and additional simulation validation processes. Fourth, this study performed the analysis without segmenting the crash data, but further studies are expected to be needed, considering driver characteristics such as older drivers. Finally, there might be various other factors that affect the safety of rest areas. The present study evaluated the safety of rest areas based on lengths of deceleration and accelerations lanes and traffic parameters, but it is necessary to conduct an additional analysis that considers various geometrical and environmental factors.

Author Contributions: Conceptualization, H.K., N.P. and J.P.; methodology, H.K., N.P. and J.P.; investigation H.K., N.P. and K.K.; data curation, K.K. and N.P., writing, H.K. and N.P; supervision, J.P. and M.A.-A. All authors have read and agreed to the published version of the manuscript.

Funding: This work was supported by the research fund of Hanyang University (HY-2020-2473).

Institutional Review Board Statement: Not applicable. 
Informed Consent Statement: Not applicable.

Data Availability Statement: Not applicable.

Conflicts of Interest: The authors declare no conflict of interest.

\section{References}

1. Korea Expressway Corporation. Available online: www.ex.co.kr (accessed on 29 June 2019).

2. Ministry of Land, Infrastructure and Transport in Korea. Guideline for Establishment and Management of Rest Area in Highways; Ministry of Land, Infrastructure and Transport in Korea: Sejong, Korea, 2019.

3. AASHTO. Highway Safety Manual; AASHTO: Washington, DC, USA, 2010.

4. FHWA, MUTCD. Manual on Uniform Traffic Control Devices; FHWA: Washington, DC, USA, 2009.

5. Romo-Martín, A.; Pérez-Acebo, H. Analysis of the Location of Service and Rest Areas and their facilities in Spanish paying motorways. Trans. Res. Procedia 2018, 33, 4-11. [CrossRef]

6. Nippon.com. Available online: www.nippon.com/en/features/jg00002/service-areas.html (accessed on 29 June 2019).

7. La Torre, F.; Domenichini, L.; Nocentini, A. Effects of stationary work zones on motorway crashes. Saf. Sci. 2017, 92, 148-159. [CrossRef]

8. Manuel, A.; El-Basyouny, K.; Islam, M.T. Investigating the safety effects of road width on urban collector roadways. Saf. Sci. 2014, 62, 305-311. [CrossRef]

9. Manan, M.M.A.; Jonsson, T.; Várhelyi, A. Development of a safety performance function for motorcycle accident fatalities on Malaysian primary roads. Saf. Sci. 2013, 60, 13-20. [CrossRef]

10. El-Basyouny, K.; Sayed, T. Measuring direct and indirect treatment effects using safety performance intervention functions. Saf. Sci. 2012, 50, 1125-1132. [CrossRef]

11. Intini, P.; Berloco, N.; Binetti, R.; Fonzone, A.; Ranieri, V.; Colonna, P. Transferred versus local Safety Performance Functions: A geographical analysis considering two European case studies. Saf. Sci. 2019, 120, 906-921. [CrossRef]

12. Han, D.; Kim, E. Estimating Acceleration and Deceleration Lane Lengths by Analyzing Vehicle Speed Variation of Rest Areas for Drowsy Drivers. J. Korea Inst. Intell. Transp. Syst. 2018, 17, 54-66. [CrossRef]

13. Seo, G.Y. A Study of Spacing and Ramp Length in the Freeway Rest Area for Sleep-Deprived Motorists. Ph.D. Thesis, Graduate School of University of Seoul, Department of Transportation Engineering in Korea, Seoul, Korea, 2018.

14. Lee, C.; Won, J. A Development of the Design Guidelines for Connecting Roads in Highway Rest Area. Int. J. Highway Eng. 2013, 15, 143-154. [CrossRef]

15. Lee, H.S.; Lee, E.E.; Seo, I.K.; Park, J.J. Developing design guidelines 1 for rest area based on the traffic safety. Int. J. Highway Eng. 2012, 14, 173-182. [CrossRef]

16. Luo, J.; Zeng, X.; Chen, Y.; Sun, D.J. Determining acceleration lane length on expressway weaving area using microscopic traffic simulation. In International Symposium for Intelligent Transportation and Smart City; Springer: Singapore, 2019; pp. 13-27.

17. Yang, G.; Wang, Z.; Xu, H.; Tian, Z. Feasibility of using a constant acceleration rate for freeway entrance ramp acceleration lane length design. J. Trans. Eng. Part A Syst. 2018, 144, 06017001. [CrossRef]

18. Qi, Y.; Zhao, Q.; Liu, S.; Qu, W.; Li, J. Determination of Freeway Acceleration Lane Length for Smooth and Safe Truck Merging, Center for Advanced Multimodal Mobility Solutions and Education; Final Report; CAMMS: Charlotte, NC, USA, 2019.

19. Chen, H.; Zhou, H.; Lin, P.S. Freeway deceleration lane lengths effects on traffic safety and operation. Safety Sci. 2014, 64, 39-49. [CrossRef]

20. Hu, J.B.; Ma, W.Q.; Wang, M. Study on the Length of Speed-Change Lane in Freeway Trumpet Interchange. Adv. Mater. Res. 2013, 779, 946-953. [CrossRef]

21. Zhou, J.; Fang, J.; Zhou, R.G. Study on the safety length of acceleration and deceleration lane of left-side ramp on freeway. In Proceedings of the 16th International Conference Road Safety on Four Continents, Beijing, China, 15-17 May 2013.

22. Hassan, Y.; Sarhan, M.; Salehi, M. Probabilistic model for design of freeway acceleration speed-change lanes. Trans. Res. Record 2012, 2309, 3-11. [CrossRef]

23. Salehi, M. Reliability-based design of freeway acceleration speed-change lanes. Ph.D. Thesis, Carleton University, Ottawa, ON, Canada, 2010.

24. Park, J.; Oh, C.; Chang, M. A Study on Variable Speed Limit Strategies in Freeway Work Zone Using Multi-Criteria Decision Making Process. J. Korean Soc. Trans. 2013, 31, 3-15. [CrossRef]

25. Rrecaj, A.A.; MBombol, K. Calibration and Validation of the VISSIM Parameters-State of the Art. TEM J. $2015,4,255$.

26. Gross, F.; Persaud, B.; Lyon, C. A Guide to Developing Quality Crash Modification Factors; No. FHWA-SA-10-032; FHWA Office of Safety: Washington, DC, USA, 2010.

27. Srinivasan, R.; Baek, J.; Council, F. Safety evaluation of transverse rumble strips on approaches to stop-controlled intersections in rural areas. J. Trans. Saf. Secur. 2010, 2, 261-278. [CrossRef]

28. Carter, D.; Srinivasan, R.; Gross, F.; Council, F. Recommended Protocols for Developing Crash Modification Factors; Final Report NCHRP 20-7 (314); NHCRP: Washington, DC, USA, 2012.

29. Park, J.; Abdel-Aty, M. Assessing the safety effects of multiple roadside treatments using parametric and nonparametric approaches. Accid. Anal. Prev. 2015, 83, 203-213. [CrossRef] [PubMed] 
30. Lao, Y.; Zhang, G.; Wang, Y.; Milton, J. Generalized nonlinear models for rear-end crash risk analysis. Accid. Anal. Prev. 2014, 62, 9-16. [CrossRef]

31. Lee, C.; Abdel-Aty, M.; Park, J.; Wang, J.H. Development of crash modification factors for changing lane width on roadway segments using generalized nonlinear models. Accid. Anal. Prev. 2015, 76, 83-91. [CrossRef]

32. Park, J.; Abdel-Aty, M. Evaluation of safety effectiveness of multiple cross sectional features on urban arterials. Accid. Anal. Prev. 2016, 92, 245-255. [CrossRef]

33. Ministry of Land, Transport and Maritime Affairs in Korea. Korea Highway Capacity Manual; Ministry of Land, Transport and Maritime: Sejong, Korea, 2013.

34. Park, J.; Abdel-Aty, M. Development of adjustment functions 1 to assess combined safety effects of multiple treatments on rural two-lane roadways. Accid. Anal. Prev. 2015, 75, 310-319. [CrossRef] [PubMed]

35. Park, J.; Abdel-Aty, M. Safety performance of combinations of traffic and roadway cross-sectional design elements at straight and curved segments. J. Transp. Eng. A Syst. 2017, 143, 04017015. [CrossRef]

36. Wang, L.; Abdel-Aty, M.; Shi, Q.; Park, J. Real-time crash prediction for expressway weaving segments. Transp. Res. Part C Emerg. Technol. 2015, 61, 1-10. [CrossRef]

37. Jeong, E.; Oh, C. Evaluating the effectiveness of active vehicle safety systems. Accid. Anal. Prev. 2017, 100, 85. [CrossRef] [PubMed] 